Implantaten en prothetische constructies 


\section{Implantaten en prothetische constructies}

Een inleiding voor mondhygiënisten

Prof. dr. C. De Baat

Prof. dr. G.M. Raghoebar

W.F.M. Pelkmans-Tijs

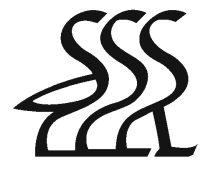

Bohn Stafleu van Loghum

Houten 2007 
Bohn Stafleu van Loghum, 2007

Alle rechten voorbehouden. Niets uit deze uitgave mag worden verveelvoudigd, opgeslagen in een geautomatiseerd gegevensbestand, of openbaar gemaakt, in enige vorm of op enige wijze, hetzij elektronisch, mechanisch, door fotokopieën of opnamen, hetzij op enige andere manier, zonder voorafgaande schriftelijke toestemming van de uitgever.

Voor zover het maken van kopieën uit deze uitgave is toegestaan op grond van artikel I6b Auteurswet $1912 \mathrm{j}^{\circ}$ het Besluit van 20 juni 1974 , Stb. 35I, zoals gewijzigd bij het Besluit van 23 augustus 1985 , Stb. 47I en artikel I7 Auteurswet I9I2, dient men de daarvoor wettelijk verschuldigde vergoedingen te voldoen aan de Stichting Reprorecht (Postbus 305I, 2130 KB Hoofddorp). Voor het overnemen van (een) gedeelte(n) uit deze uitgave in bloemlezingen, readers en andere compilatiewerken (artikel I6 Auteurswet 1912) dient men zich tot de uitgever te wenden.

Samensteller(s) en uitgever zijn zich volledig bewust van hun taak een betrouwbare uitgave te verzorgen. Niettemin kunnen zij geen aansprakelijkheid aanvaarden voor drukfouten en andere onjuistheden die eventueel in deze uitgave voorkomen.

ISBN 9789031343812 NUR 887

Ontwerp omslag: TEFF, Hurwenen

Ontwerp binnenwerk: Studio Bassa, Culemborg Automatische opmaak: Pre Press, Zeist

Illustraties: Idiomorf, Utrecht

Bohn Stafleu van Loghum

Het Spoor 2

Postbus 246

3990 GA Houten

www.bsl.nl
Distributeur in België: Standaard Uitgeverij Mechelsesteenweg 203 20I8 Antwerpen

www.standaarduitgeverij.be 


\section{Woord vooraf}

Het plan om dit boek samen te stellen, is ontstaan naar aanleiding van een verzoek van een aantal ervaren mondhygiënisten die bij hun werk op een universiteitsafdeling voor mondziekten, kaakchirurgie en bijzondere tandheelkunde dagelijks in aanraking kwamen met patiënten die recent of al langer geleden waren behandeld met implantaten. Deze mondhygiënisten waren van mening dat zij onvoldoende inzicht hadden in de chirurgische en prothetische aspecten van de orale implantologie. Tijdens hun opleiding was de orale implantologie voor enkelen in beperkte mate en voor anderen zelfs helemaal niet aan de orde geweest. Nu behandelingen met implantaten in specifieke praktijken voor bijvoorbeeld kaak- en aangezichtschirurgie, implantologie en parodontologie, maar ook in algemene praktijken steeds meer voorkomen, is theoretische en praktische scholing van mondhygiënisten op dit gebied een dringende behoefte.

In dit boek is beknopt het hele traject van een behandeling met implantaten beschreven, van het opstellen van het behandelplan tot en met de nazorg. Door hiervan kennis te nemen, ontstaat meer begrip voor de noodzaak alle onderdelen van de implantaten en de prothetische constructies onder controle te houden en de noodzaak de patiënten te blijven begeleiden bij de benodigde zelfzorg. Om alle achtergronden goed te kunnen begrijpen, is wel enige kennis van de orale anatomie en fysiologie vereist.

Wij als auteurs hebben met plezier aan dit boek gewerkt. Bij de samenstelling hebben wij welwillend hulp gekregen van een aantal collega's die wij hiervoor bijzonder hartelijk danken. Deze collega's zijn in alfabetische volgorde: drs. P. de Baat, mw. E.M.E.J. Clerx, mw. drs. J.F.A. van Elswijk, prof. dr. H.J.A. Meijer, drs. K.H. Phoa, dr. C. Stellingsma, prof. dr. A. Vissink en mw. A. Vos.

Cees de Baat

Gerry Raghoebar

Wil Pelkmans-Tijs 
Inhoud

Woord vooraf

I Inleiding, indicaties en contra-indicaties $\quad$ I I

I.I Inleiding I I

I.2 Indicaties voor implantatie I 4

I.3 Contra-indicaties voor implantatie I 6

I.3.I Diabetes mellitus I 6

I.3.2 Botafwijkingen en tekort aan bot I7

I.3.3 Bloedafwijkingen 20

I.3.4 Cardiovasculaire afwijkingen 20

I.3.5 Medicatie 20

I.3.6 Allergie voor titanium 23

I.3.7 Grote tong 23

I.3.8 Ongunstige relatie tussen boven- en onderkaak 23

$\begin{array}{ll}\text { I.3.9 Parafuncties } & 23\end{array}$

I.3.IO Slechte mondhygiëne en ontstoken slijmvlies 23

I.3.II Hyposalivatie 24

I.3.I2 Radiotherapie in het hoofd-halsgebied 24

I.3.I3 Onvolgroeide status 24

I.3.I4 Zwangerschap 25

I.3.I5 Roken $\quad 25$

$\begin{array}{ll}\text { Literatuur } & 25\end{array}$

2 Implantaten, osseo-integratie en het contact met het mondslijmvlies $\quad 26$

2.I Inleiding 26

2.2 Materialen en uitvoeringen van implantaten 26

2.3 Osseo-integratie van een implantaat 29

2.4 Contact tussen implantaat en mondslijmvlies 32

Literatuur 33

3 Opstellen behandelplan $\quad 35$

3.I Inleiding 35 


\begin{tabular}{|c|c|}
\hline 3.2 & Anamnese \\
\hline $3 \cdot 3$ & Extraoraal onderzoek \\
\hline $3 \cdot 4$ & Intraoraal onderzoek \\
\hline $3 \cdot 5$ & Röntgenonderzoek \\
\hline 3.6 & Opstellen van een behandelplan \\
\hline 3.6.I & Beschikbaar botvolume \\
\hline 3.6 .2 & Vaste of uitneembare prothetische constructie \\
\hline 3.6 .3 & Aantal implantaten \\
\hline 3.6 .4 & Positie implantaten \\
\hline 3.6 .5 & Eenfase- of tweefasensysteem \\
\hline 3.6.6 & Belasting implantaten \\
\hline 3.6.7 & Implantaatopbouwen \\
\hline 3.6.8 & Mesostructuur \\
\hline 3.6 .9 & Combinatie met natuurlijke gebitselementen \\
\hline & Literatuur \\
\hline 4 & Pre-implantaire chirurgie \\
\hline 4.I & Inleiding \\
\hline 4.2 & $\begin{array}{l}\text { Verbreding van een scherpe en smalle processus } \\
\text { alveolaris }\end{array}$ \\
\hline $4 \cdot 3$ & Splijten van de processus alveolaris \\
\hline $4 \cdot 4$ & Botopbouw in de bovenkaak \\
\hline $4 \cdot 5$ & Geleide botregeneratie \\
\hline 4.6 & Sinusbodemverhoging \\
\hline $4 \cdot 7$ & Le Fort-I-osteotomie met interpositie van bot \\
\hline 4.8 & Botopbouw in de onderkaak \\
\hline $4 \cdot 9$ & Distractieosteogenese \\
\hline \multirow[t]{2}{*}{$4 \cdot 10$} & Slotbeschouwing \\
\hline & Literatuur \\
\hline
\end{tabular}

5 Chirurgische procedure en tijdelijke prothetische constructies 60

5.I Inleiding 60

5.2 Onderkaak 60

$5 \cdot 3$ Bovenkaak 65

5.4 Nazorg 68

5.5 Tijdelijke prothetische constructies 68

5.5.I Partieel betande kaak 69

5.5.2 Edentate onderkaak 69

$\begin{array}{lll}5 \cdot 5 \cdot 3 & \text { Edentate bovenkaak } & 69\end{array}$

5.6 Slotbeschouwing 70

$\begin{array}{ll}\text { Literatuur } & 7 \text { I }\end{array}$ 
6 Overkappingsprothesen en mesostructuren 72

$\begin{array}{ll}\text { 6.I Inleiding } & 72\end{array}$

$\begin{array}{ll}6.2 & 72\end{array}$

6.3 Definitieve afdrukken 74

$\begin{array}{lll}6.4 & \text { Beetregistratie } & 76\end{array}$

6.5 Passen opstelling in was 80

6.6 Passen mesostructuur $8 \mathrm{I}$

6.7 Plaatsen bovenprothese, mesostructuur en

$\begin{array}{lll}6.8 & \text { Nazorg } & 82\end{array}$

$\begin{array}{lr}\text { Literatuur } & 82\end{array}$

$7 \quad$ Complicaties en hun behandeling $\quad 84$

7.I Inleiding 84

7.2 Complicaties tijdens chirurgische behandeling 84

7.2.I Bloeding 85

$\begin{array}{ll}7.2 .2 & \text { Nervusbeschadiging } \\ 7.2 .3\end{array}$

7.2.3 Perforatie sinus maxillaris of neusbodem 86

7.2.4 Fractuur onderkaak 86

7.2.5 Emfyseem en luchtembolie $\quad 87$

7.2.6 Fractuur implantaat of instrumentarium 88

7.2.7 Aspiratie of inslikken corpus alienum 88

7.2.8 Te weinig botvolume 88

7.2.9 Onvoldoende stabiliteit implantaat 89

7.3 Complicaties na chirurgische behandeling 89

7.3.I Nabloeding 89

$7 \cdot 3.2$ Oedeem 90

$7 \cdot 3 \cdot 3$ Hematoom $9 \mathrm{I}$

7.3.4 Gestoorde wondgenezing 92

$\begin{array}{lll}7 \cdot 3 \cdot 5 & \text { Ontsteking } & 92\end{array}$

7.3.6 Onvoldoende gekeratiniseerd slijmvlies 93

7.3.7 Fractuur implantaat(onderdeel) 95

$\begin{array}{ll}7.4 & \text { Slotbeschouwing }\end{array}$

$\begin{array}{ll}\text { Literatuur } & 96\end{array}$

$8 \quad$ Nazorg door de mondhygiënist $\quad 97$

$\begin{array}{ll}\text { 8.I Inleiding } & 97\end{array}$

8.2 Anamnese 98

8.3 Extraoraal onderzoek 99

$\begin{array}{ll}8.4 & \text { Intraoraal onderzoek }\end{array}$

8.5 Röntgenonderzoek I 04

8.6 Behandelingen I 04

8.7 (Her)instructie I05 
8.8 Vaststellen controletermijn $\quad$ I 07

$\begin{array}{ll}\text { Literatuur } & \text { I } 07\end{array}$

Register $\quad$ I 09 